\title{
A mutant BRAF V600E-specific immunohistochemical assay: correlation with molecular mutation status and clinical outcome in colorectal cancer
}

\author{
Fiona Day • Andrea Muranyi • Shalini Singh • Kandavel Shanmugam • \\ David Williams • David Byrne • Kym Pham • Michelle Palmieri • Jeanne Tie • \\ Thomas Grogan • Peter Gibbs • Oliver Sieber • Paul Waring • Jayesh Desai
}

Received: 16 January 2014 / Accepted: 9 May 2014 / Published online: 27 May 2014

(C) The Author(s) 2014. This article is published with open access at Springerlink.com

\begin{abstract}
The B-type Raf kinase (BRAF) V600E mutation is a well-established biomarker for poor prognosis in metastatic colorectal cancer (mCRC) and is a highly attractive drug target. A barrier to the development of new therapies targeting BRAF V600E in $\mathrm{mCRC}$ is the low prevalence of mutations (approximately $10 \%$ ) and the current need for access to sequencing-based technologies which are not routinely
\end{abstract}

Paul Waring and Jayesh Desai contributed equally to this study.

F. Day $\cdot$ M. Palmieri $\cdot$ J. Tie $\cdot$ P. Gibbs $\cdot$ O. Sieber $\cdot$ J. Desai

Ludwig Colon Cancer Initiative Laboratory, Ludwig Institute for

Cancer Research, Parkville, VIC, Australia

F. Day $\cdot$ M. Palmieri $\cdot$ J. Tie $\cdot$ P. Gibbs $\cdot$ O. Sieber $\cdot$ J. Desai Faculty of Medicine, Dentistry and Health Sciences, Department of Surgery, University of Melbourne, Parkville, VIC, Australia

A. Muranyi $\cdot$ S. Singh $\cdot$ K. Shanmugam $\cdot$ T. Grogan

Ventana Medical Systems, Inc., Tucson, AZ, USA

D. Williams

Department of Pathology, Austin Health, Heidelberg, VIC, Australia

D. Byrne

Pathology Department, Peter MacCallum Cancer Centre, East

Melbourne, VIC, Australia

K. Pham $\cdot$ P. Waring

Faculty of Medicine, Dentistry and Health Sciences, Department of Pathology, University of Melbourne, Parkville, VIC, Australia

J. Tie $\cdot$ P. Gibbs $\cdot$ J. Desai

Department of Medical Oncology, Royal Melbourne Hospital,

Parkville, VIC, Australia

J. Tie $\cdot$ P. Gibbs $\cdot$ J. Desai $(\bowtie)$

Department of Medical Oncology, Western Hospital, Footscray, VIC, Australia

e-mail: Jayesh.Desai@mh.org.au available outside of large cancer centres. Availability of a standardised immunohistochemistry (IHC) test, more suited to routine pathology practice, would provide much broader access to patient identification. We sought to evaluate the accuracy and clinical utility of a recently developed BRAF V600E IHC method as a prognostic biomarker in a large cohort of community-based CRC patients. Archival tumour samples from 505 patients with stage I-IV CRC were immunohistochemically tested with two antibodies, pBR1 for total BRAF and VE1 for BRAF V600E. Cases were assessed by two blinded pathologists, and results were compared to $B R A F$ V600E mutation status determined using DNA sequencing. Discordant cases were retested with a $B R A F$ V600E SNaPshot assay. BRAF mutation status was correlated with overall survival (OS) in stage IV CRC. By DNA sequencing and IHC, 505 and 477 patients were respectively evaluable. Out of 477 patients, $56(11.7 \%)$ had $B R A F$ V600E mutations detected by sequencing and $63(13.2 \%)$ by IHC. Using DNA sequencing results as the reference, sensitivity and specificity for IHC were $98.2 \%(55 / 56)$ and $98.1 \%$ (413/ $421)$, respectively. IHC had a positive predictive value (PPV) of $87.3 \%(55 / 63)$ and a negative predictive value (NPV) of $99.8 \%$ (413/414). Compared to DNA sequencing plus retesting of available discordant cases by SNaPshot assay, IHC using the VE1 antibody had a $100 \%$ sensitivity (59/59), specificity (416/416), NPV (416/416) and PPV (59/59). Stage IV CRC patients with BRAF V600E protein detected by IHC exhibited a significantly shorter overall survival (hazard ratio= $2.20,95 \%$ CI 1.26-3.83, $p=0.005$ ), consistent with other published series. Immunohistochemistry using the BRAF V600E VE1 antibody is an accurate diagnostic assay in CRC. The test provides a simple, clinically applicable method of testing for the BRAF V600E mutation in routine practice. 
Keywords Immunohistochemistry · VE1 · BRAF V600E . Colorectal cancer

\section{Introduction}

A serine/threonine kinase of the MAPK-ERK signalling pathway, B-type Raf kinase (BRAF), and other RAF family members are usually activated by GTP-bound RAS signalling downstream of the epidermal growth factor receptor (EGFR) or in response to other mitogens [1]. Mutant BRAF, however, displays constitutive activation when affected by missense mutation [2], most commonly V600E. Approximately $10 \%$ of colorectal cancers (CRCs) harbour BRAF V600E [2-4], and this subset is associated with a significantly poorer survival [5-7] in patients with metastatic disease. $B R A F$ mutation may also predict lack of benefit from anti-EGFR therapy $[8,9]$ in metastatic CRC, although reports are conflicting [10]. The current clinical value of $B R A F$ V600E detection is the delineation of hereditary non-polyposis colorectal cancer (HNPCC)-associated tumours (BRAF wild type) from sporadic CRCs (BRAF V600E mutant) in mismatch repairdeficient colorectal disease [11-13] and rational patient enrolment to clinical trials testing BRAF inhibitors [6].

Various methods of genotyping tumour samples for $B R A F$ status are currently used in diagnostic and research laboratories, ranging from traditional Sanger sequencing [14] to quantitative pyrosequencing [15], mutation-specific real-time polymerase chain reaction (RT-PCR) assays [16] and mass spectrometry-based methods [17]. Common to all these methods, however, is the requirement for DNA extraction from tissue and the need for rigorous protocols to minimise the impact of contamination of non-tumour cells on the overall tumour to non-tumour cell ratio.

Importantly, at this point in time, the expertise and infrastructure required for DNA-based genotyping methods are frequently available only at academic centres and reference laboratories. Testing for $B R A F \mathrm{~V} 600 \mathrm{E}$ therefore requires multiple steps and coordination between the primary site and reference laboratory, resulting in sample transit costs and diagnostic delays. Until genomic-based testing becomes available in routine community-based pathology laboratories, the complexity involved in such testing will continue to serve as an impediment to providing a patient's $B R A F$ status to their treating clinician.

A monoclonal antibody specific to the BRAF V600E kinase, VE1, has recently been described [18] and offers the advantages of immunohistochemical determination of tumour $B R A F$ mutation status, no requirement for DNA purification, low cost and the ability to perform testing on formalin-fixed paraffin-embedded (FFPE) tissue in routine histopathology laboratories. To date, immunohistochemistry with VE1 has been applied to the detection of BRAF V600E in brain metastases of varied primary sites [19], papillary thyroid carcinoma [20, 21], Langerhans cell histiocytosis [22, 23], ovarian carcinomas [24, 25], melanoma [26-28], lung adenocarcinoma [29] and hairy cell leukemia [30]. A recently published study by Sinicrope et al. explored the VE1 antibody in a carefully preselected group of 75 patients with stage III colorectal cancer, for whom $B R A F$ mutation status had already been determined [31]. In another recent study examining the utility of BRAF immunohistochemistry (IHC) in microsatellite unstable CRC, Toon et al. [32] compared BRAF IHC with conventional PCR-based molecular methods for $B R A F$ V600E detection in 216 patients with CRC. In a further cohort, they also performed IHC to mismatch repair (MMR) proteins and BRAF V600E in a larger cohort of 1,403 patients with $\mathrm{CRC}$ but failed to also validate this using conventional sequencing-based molecular techniques.

In this study, we aimed to determine the sensitivity, specificity and predictive values of VE1 immunohistochemistry for BRAF V600E in a large community-based and unselected cohort $(n=505)$ of patients with CRC, with the intent of determining how this could inform the use of this IHC-based antibody in routine practice. FFPE tumour samples were annotated for clinical outcomes and had been previously assessed for $B R A F$ status by direct (Sanger) sequencing.

\section{Methods}

\section{Colorectal tissue samples}

Primary tumour and matched normal tissue samples were obtained from an unselected community-based cohort of 505 patients with CRC undergoing surgery at three hospitals in Melbourne, Australia: the Royal Melbourne, Melbourne Private and Western Hospitals. Resected tumours included those from the proximal colon, distal colon and rectum, and all disease stages (I-IV) were represented. This study was approved by the ethics committees of these hospitals and the University of Melbourne.

Tissue microarrays (TMAs) comprised of 1-mm-diameter tissue cores were constructed from the FFPE surgical specimens. Up to four tumour and two normal colon tissue cores were embedded per patient. Tumour cores were harvested from the areas of densest tumour cell percentage. Based on examination of hematoxylin and eosin (H\&E)-stained TMA sections by two anatomical pathologists, cores were deemed to contain sufficient tumour sample for immunohistochemical analysis in 491 patients (97\%) (Fig. 1).

\section{Sanger sequencing}

All patients of the cohort were characterised for $B R A F$ codon 600 mutation status based on Sanger sequencing at the 


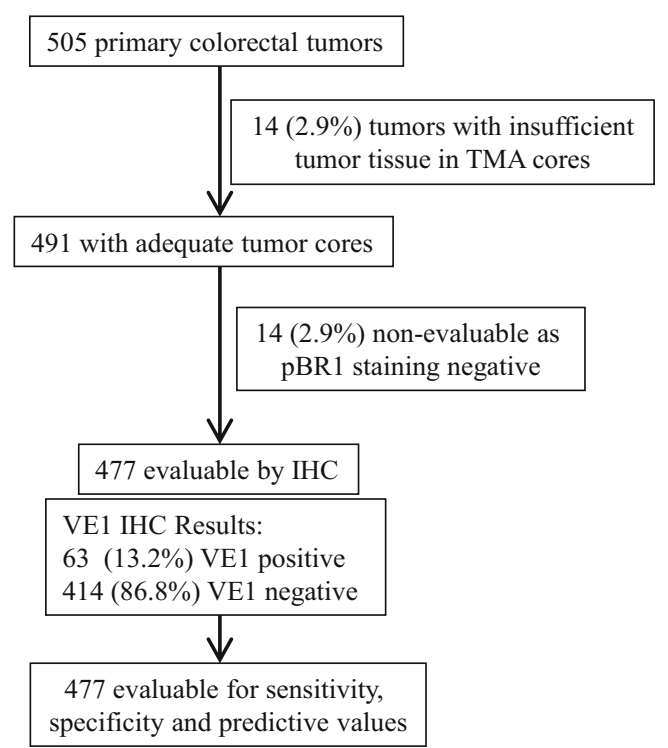

Fig. 1 Workflow and results for immunohistochemistry on tissue microarray (TMA) sections

Ludwig Institute Parkville, Melbourne, prior to immunohistochemical analysis of TMAs. Tumours were microdissected from the originating FFPE blocks, and the purified DNA was subjected to PCR and sequencing using primers and methods previously described [6]. Samples with indeterminate sequencing traces on first analysis were subjected to repeat PCR and sequencing.

\section{Immunohistochemistry}

Total BRAF and BRAF V600E-mutant proteins were detected by immunohistochemistry using rat anti-panBRAF monoclonal antibody (clone pBR1) and mouse anti-BRAF V600E monoclonal antibody (clone VE1), respectively, both kindly provided by Dr A. von Deimling from Ruprecht-KarlsUniversity, Heidelberg [18]. All assays were performed on a BenchMark XT automated slide stainer at Ventana Medical Systems, Inc., Tucson, AZ.

Sections from TMAs were freshly cut to $4 \mu \mathrm{m}$ and dried at $80{ }^{\circ} \mathrm{C}$ for $15 \mathrm{~min}$. The presence of total BRAF protein was detected using ultraView Universal DAB Detection Kit (Ventana) where ultraView Universal HRP Multimer was substituted for an HRP-conjugated goat anti-rat secondary antibody. The staining procedure included deparaffinisation, pretreatment using standard Cell Conditioning 1, incubation with pan-BRAF antibody (diluted 1:8) at $37^{\circ} \mathrm{C}$ for $16 \mathrm{~min}$ and treatment with ultrawash.

The BRAF V600E mutation-specific IHC assay was completed with OptiView DAB IHC Detection Kit (Ventana). Briefly, the tissue sections were deparaffinised, heat pretreated in Cell Conditioning 1 for $64 \mathrm{~min}$ and followed by inactivation of the endogenous peroxidases. Specimens were incubated with VE1 hybridoma supernatant (diluted 1:3) at $37^{\circ} \mathrm{C}$ for $16 \mathrm{~min}$.

Following the chromogenic detection, all slides were counterstained with Hematoxylin II and Bluing Reagent (Ventana) for $4 \mathrm{~min}$ each and coverslips were applied.

The immmunostained slides were evaluated independently by two pathologists (S.S. and D.W.) blinded to the $B R A F$ V600E mutation status as determined by sequencing. First, pan-BRAF IHC was assessed for the presence of total BRAF cytoplasmic staining within invasive tumour cells. Cases were scored as unevaluable when total BRAF expression could not be detected, and they were excluded from further immunohistochemical analysis. Next, BRAF V600E (VE1) immunostained slides were evaluated for the presence or absence of BRAF V600E protein expression. Immunoreactivity was scored positive when there was unequivocal cytoplasmic staining above background in the majority of invasive viable tumour cells. Any nuclear staining, weak cytoplasmic staining of isolated tumour cells or focal confluent staining of tumour cells in a tumour that otherwise showed no staining was scored as immunonegative.

\section{SNaPShot assays}

DNA was extracted with QIAamp DNA FFPE Tissue Kit (Qiagen) from tumour cells microdissected from unstained FFPE tissue slides and then quantitated using a Qubit ${ }^{\circledR}$ fluorometer (Invitrogen, Grand Island, NY, USA). Purified tumour DNA was PCR-amplified for 30 cycles at 94 and $72{ }^{\circ} \mathrm{C}$, for $45 \mathrm{~s}$ each, using BRAF exon 15 forward (TTCATAATGCTTGCTCTGATAGG) and reverse (AGTA ACTCAGCAGCATCTCAGG) primers (GeneWorks, Thebarton, SA, Australia) and AmpliTaq Gold ${ }^{\circledR}$ DNA Polymerase (Applied Biosystems, Grand Island, NY, USA). The 246-bp products were treated with ExoSAP-IT (USB) at $37{ }^{\circ} \mathrm{C}$ for $30 \mathrm{~min}$ and $80{ }^{\circ} \mathrm{C}$ for $15 \mathrm{~min}$ to remove excess nucleotides and primers. HPLC-purified detection primer ((C) 5 TGATTTTGGTCTAGCTACAG) (GeneWorks) was added to the cleaned product together with PRISM SNaPshot Multiplex Ready Reaction Mix (Applied Biosystems) containing fluorescent ddNTPs. The detection primer was extended by thermocyling for 35 cycles at $96{ }^{\circ} \mathrm{C}$ for $10 \mathrm{~s}, 48{ }^{\circ} \mathrm{C}$ for $1 \mathrm{~min}$ and then $60{ }^{\circ} \mathrm{C}$ for $30 \mathrm{~s}$. Excess nucleotides and primers were removed by shrimp alkaline phosphatase (Sigma, St. Louis, MO, USA) treatment at $37{ }^{\circ} \mathrm{C}$ for $1 \mathrm{~h}$ followed by $75{ }^{\circ} \mathrm{C}$ for $15 \mathrm{~min}$, and the cleaned fragments were run in $\mathrm{Hi}-\mathrm{Di}$ Formamide (Applied Biosystems) through an ABI 3130xl genetic analyser (Applied Biosystems) and analysed by GeneMapper $^{\circledR}$ fragment analysis software. A mutation was called when the area under the fluorescent peak for the mutant allele was greater than five times the background relative fluorescent units. This method has been reported to detect mutations in tissue samples containing $\leq 5 \%$ tumour cells [33-35]. 
Statistical analyses

Sensitivity, specificity and predictive values for IHC in comparison to direct DNA sequencing were determined as per convention [36, 37]. Overall survival (OS) in stage IV disease was defined as the time from diagnosis of metastatic CRC to death from any cause. Analyses included patients with de novo stage IV disease and those diagnosed with distance recurrence after prior treatment of earlier stage disease. Survival times were estimated using the Kaplan-Meier method, and results were compared using the log-rank test. Statistical significance was defined as $p<0.05$.

\section{Results}

\section{BRAF V600E status}

Using Sanger sequencing, $11.7 \%$ (59/505) of stage I-IV CRC patients were $B R A F \mathrm{~V} 600 \mathrm{E}$ mutation positive and the remainder were wild-type (WT). No tumour carried non-V600E mutations at codon 600 . Of the 491 patients with adequate TMA tumour tissue for interpretation of total BRAF (pBR1 antibody) and BRAF V600E (VE1 antibody) immunohistochemistry, 14 patients $(2.9 \%)$ were negative for $\mathrm{pBR} 1$ staining and were accordingly deemed unevaluable for $B R A F$ status by IHC (Fig. 1). Of the 477 'evaluable' (pBR1 positive) patients, 63 (13.2\%) were positive for VE1 ('BRAF V600E') and 414 (86.8\%) were negative for VE1 staining ('BRAF WT') (Fig. 2). Of the 63 pBR1- and VE1-positive cases, the majority showed moderate to strong homogeneous cytoplasmic staining with the VE1 antibody. Occasional cases showed uniformly weak staining or focal patches of no staining in otherwise clearly positive tumours. Of the 414 pBR1-positive and VE1-negative cases, 8 (1.9 \%) showed weak patchy positivity for VE1 (Fig. 3). All eight such heterogeneous cases were $B R A F$ WT by sequencing. In normal colonic mucosa, nuclear VE1 staining was frequently observed in surface epithelial cells (Fig. 4).

The clinicopathological features and IHC results for the evaluable patient population are shown in Table 1. A higher frequency of BRAF V600E positivity was seen in female patients and CRCs resected from the right colon, exhibiting poor differentiation or with microsatellite instability (MSI). These results are consistent with the findings of multiple prior cohort studies typing V600 mutations using DNA-based methods [38-40].

The sensitivity, specificity and predictive values for IHC were determined in the evaluable population as compared to the results from Sanger sequencing, which was considered to be the current gold standard for the determination of $B R A F$ genotype. The sensitivity of VE1 staining for $B R A F$ V600E was $98.2 \%(55 / 56)$, specificity $98.1 \%$ (413/421), negative predictive value (NPV) $99.8 \%(413 / 414)$ and positive predictive value (PPV) $87.3 \%(55 / 63)$ (Table 2).

Further investigation of discordant cases

Based on the Sanger sequencing results and IHC conducted on TMA cores, there were eight apparent IHC false-positive cases and one apparent IHC false-negative case (Table 2, Fig. 5). We sought to resolve these nine discordant cases by retesting and applying additional methods to detect or exclude $B R A F$ V600E. To exclude the possibilities of sample mismatches or sampling error arising from the use of TMA cores for IHC, whole tissue sections were cut from the original FFPE tissue blocks and reprocessed for BRAF sequencing and IHC. In addition, to increase the sensitivity of DNAbased determination of BRAF mutation status, BRAF SNaPshot assays [34, 35] were performed on DNA extracted from tumour cells microdissected from sections adjacent to the original tissue sections utilised.

The original archival FFPE tissue blocks could be obtained for these further analyses from seven of the nine patients with discordant results, comprising six IHC false-positive and the single IHC-false negative case (Fig. 5). For three of the initial IHC false-positive cases, reanalyses confirmed the presence of the BRAF V600E mutation upon IHC and SNaPshot (allele frequencies of 33, 27 and $3 \%$ ), but Sanger sequencing again missed these mutant cases. In contrast, the other three initial IHC false-positive cases were found to be WT upon reanalysis with Sanger sequencing, SNaPshot and IHC on the whole mount slides (two with $0 \%$ and one with $10 \%$ of cells staining). Of the three cases erroneously VE1 positive on TMA IHC, review of the tissue core harvest sites on the VE1 whole sections showed sampling from heterogeneously stained areas in two of the three cases.

The single initial IHC false-negative case was confirmed to be BRAF V600E by resequencing and SNaPshot analysis (mutant allele frequency of $17 \%$ ) and showed corresponding VE1-positive staining in $47 \%$ of tumour cells in the whole tissue section. Most discrepancies were, therefore, due to either low sensitivity of Sanger sequencing and/or heterogeneous VE1 antibody staining compounded by sampling error from the use of TMAs. When the two discordant cases with unavailable blocks for retesting were excluded, the VE1 antibody had a $100 \%$ sensitivity, specificity, NPV and PPV in the population of reevaluable cases $(n=475)$ (Table 3$)$.

Prognostic significance of VE1 positivity

We determined the prognostic significance of VE1 positivity in patients of the evaluable cohort with de novo $(n=108)$ or recurrent $(n=87)$ metastatic disease using final results after investigation of the discordant cases with whole mount IHC and SNaPShot assays. Survival data was available for 188 
Fig. 2 Representative images of pBR1-positive tumours either positive or negative for VE1. The upper panels represent a BRAF wild-type tumour, showing a hematoxylin and eosin (H\&E), b total BRAF (pBR1) expression and $\mathbf{c}$ lack of BRAF V600E (VE1) protein. The lower panels demonstrate a confirmed BRAF V600E mutant tumour displaying d H\&E and e total BRAF (pBR1) and $\mathbf{f}$ BRAF V600E (VE1) protein expression
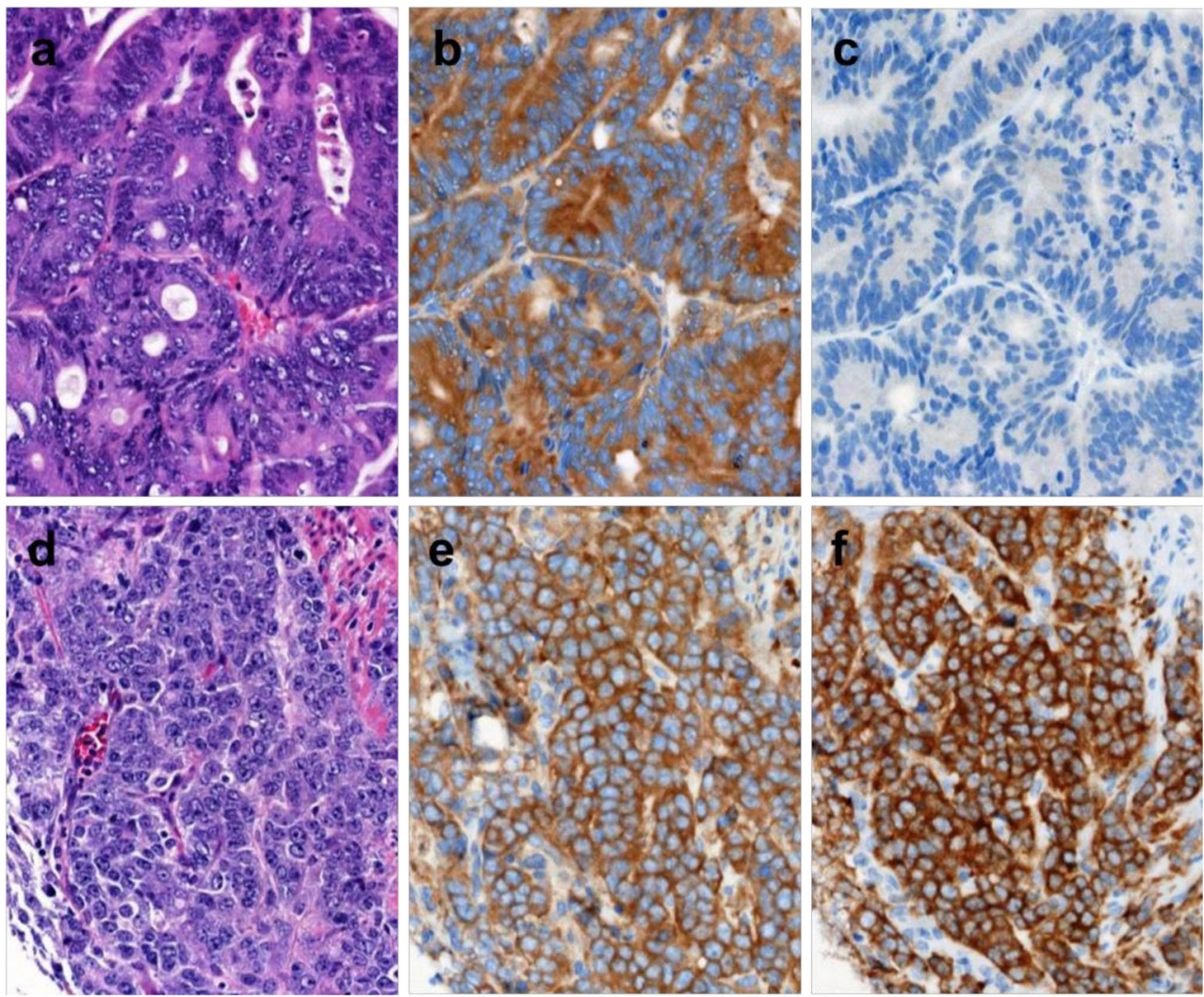

(96\%) patients of this subgroup. The median OS with metastatic disease for patients with $B R A F$ V600E tumours on IHC was 275 days compared to 518 days for those with $B R A F \mathrm{WT}$. The hazard ratio for OS with $B R A F$ V600E was $2.20(95 \% \mathrm{CI}$ $1.26-3.83, p=0.005$ ) (Fig. 6).

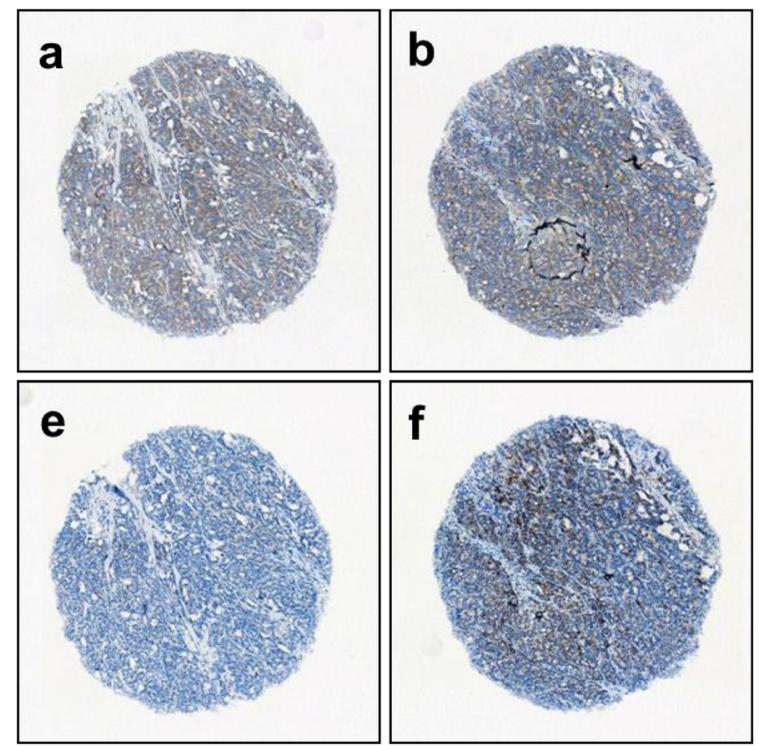

Fig. 3 Representative images demonstrating heterogeneous staining of mutant BRAF V600E protein. a-d pan-BRAF IHC (pBR1) detects total BRAF within all cores of a single case. $\mathbf{e}-\mathbf{h}$ Using the mutation-specific

\section{Discussion}

Mutation of $B R A F$ V600E is a well-validated poor prognostic marker in metastatic CRC [5-7], as well as a discriminator between HNPCC-related disease and sporadic MSI CRCs

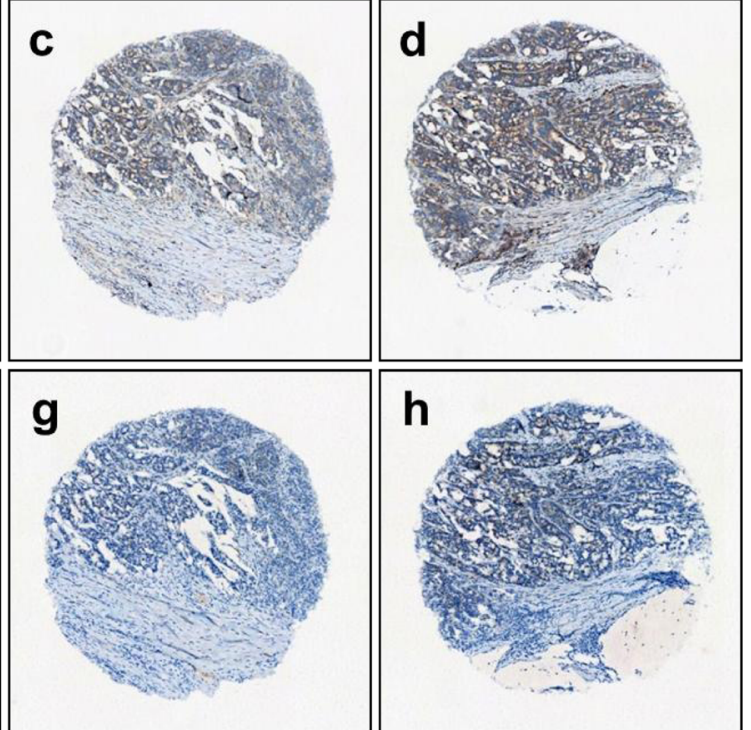

antibody VE1, mutant BRAF V600E is only present within cores $\mathbf{f}$ and $\mathbf{h}$ and absent within cores $\mathbf{e}$ and $\mathbf{g}$ of the same case 
Fig. 4 Representative images of normal colon indicating a hematoxylin and eosin (H\&E), b cytoplasmic total BRAF expression (pBR1) and $\mathbf{c}$ both cytoplasmic and nuclear staining in normal colonic epithelium (VE1)
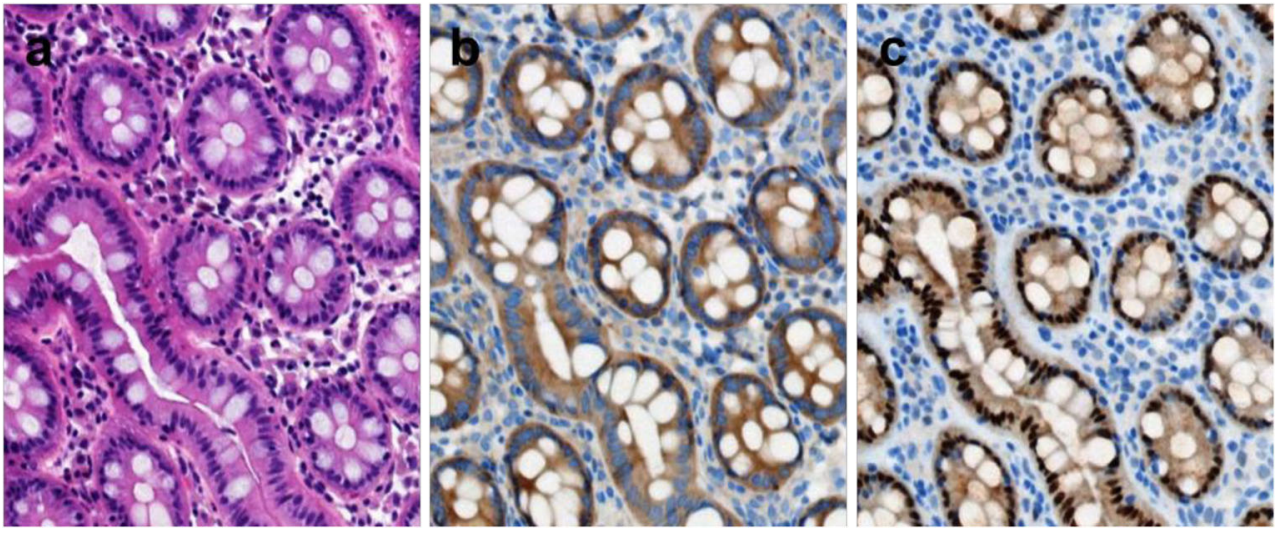

[11-13]. Perhaps the greatest promise of $B R A F$ V600E detection, however, is in the application of targeted therapies in the emerging era of personalised medicine. While $B R A F$-mutant colorectal cancer has not demonstrated the same responsiveness to single-agent BRAF inhibitors seen in metastatic melanoma [41, 42], recent research findings show encouraging headway in the characterisation of CRC resistance mechanisms [42-44]. Clinical studies combining BRAF inhibitors

Table 1 Clinical characteristics of patients with colorectal cancer evaluable by immunohistochemistry $(n=477)$

\begin{tabular}{|c|c|c|}
\hline Feature & $n(\%)$ & $\begin{array}{l}B R A F \text { V600E IHC } \\
\text { positive, } n(\%)\end{array}$ \\
\hline Mean age (years) & 70.5 & \\
\hline \multicolumn{3}{|l|}{ Gender } \\
\hline Male & $193(40)$ & $10(5)$ \\
\hline Female & $282(59)$ & $53(19)$ \\
\hline Unknown & $2(<1)$ & $0(0)$ \\
\hline \multicolumn{3}{|l|}{ Tumour site } \\
\hline Right colon & $200(42)$ & $52(26)$ \\
\hline Left colon & $193(40)$ & $8(4)$ \\
\hline Rectum & $82(17)$ & $3(4)$ \\
\hline Unknown & $2(<1)$ & $0(0)$ \\
\hline \multicolumn{3}{|l|}{ Tumour stage } \\
\hline I & $27(6)$ & $2(7)$ \\
\hline II & $148(31)$ & $23(16)$ \\
\hline III & $192(40)$ & $23(12)$ \\
\hline IV & $108(23)$ & $15(14)$ \\
\hline Unknown & $2(<1)$ & $0(0)$ \\
\hline \multicolumn{3}{|l|}{ Differentiation } \\
\hline Well moderate & $304(64)$ & $25(8)$ \\
\hline Poor & $161(34)$ & $35(22)$ \\
\hline Unknown & $12(3)$ & $3(25)$ \\
\hline \multicolumn{3}{|l|}{ Microsatellite status } \\
\hline Microsatellite stable & $371(78)$ & $24(6)$ \\
\hline Microsatellite unstable & $96(20)$ & $39(41)$ \\
\hline Unknown & $10(2)$ & $0(0)$ \\
\hline
\end{tabular}

with EGFR inhibitors, PI3K inhibitors or MEK inhibitors are now underway based on these recent data and will require accurate, efficient identification of patients with $B R A F$-mutant CRC.

We report a large series of community-based colorectal cancers screened for BRAF V600E mutation using the novel, mutation-specific monoclonal antibody VE1. In this study, blinded interpretation of VE1 IHC on CRC cores embedded in TMAs showed $98.2 \%$ sensitivity, $98.1 \%$ specificity, $87.3 \%$ PPV and $99.8 \%$ NPV against BRAF genotype determined by direct sequencing. Similar sensitivities and specificities for VE1 have been reported in papillary thyroid cancer, lung cancer and melanoma [20, 27-29]. Given that positive IHC results are likely to be verified by gene-based mutation detection methods and accurate identification of $B R A F$ mutation is expected to facilitate access to novel targeted therapies, the NPV of VE1 IHC is of the highest importance. Only one sample in this study was falsely negative on VE1 TMA IHC and subsequently shown to be clearly VE1 positive on wholesection staining. The resolution of discordant findings for this case, and the further six available TMA IHC false-positive cases, by additional methods is reasonable in the context of this particular study. It is important to note that whole-section IHC would be conducted in routine clinical practice, rather than via the creation of TMAs. In addition, numerous genotyping methods have been recently demonstrated to be more sensitive than Sanger sequencing [15-17, 27]. The sensitivity, specificity, PPV and NPV were each recalculated as $100 \%$ in the fully evaluable patient population. As

Table 2 Initial determination of $B R A F$ V600E using immunohistochemistry on TMA sections versus determination by Sanger sequencing

\begin{tabular}{lll}
\hline BRAF V600E results $(n=477)$ & IHC positive & IHC negative \\
\hline Sequencing positive & $55 a$ & $1 b$ \\
Sequencing negative & $8 c$ & $413 d$ \\
\hline
\end{tabular}

Sensitivity $(a / a+b)=55 / 56(98.2 \%)$; specificity $(d / d+c)=413 / 421$ (98.1\%); negative predictive value $(d / d+b)=413 / 414(99.8 \%)$; positive predictive value $(a / a+c)=55 / 63(87.3 \%)$ 
Fig. 5 Initial results and subsequent investigation of discordance between TMA IHC and Sanger sequencing results. $I H C$ immunohistochemistry, FFPE formalin-fixed, paraffinembedded

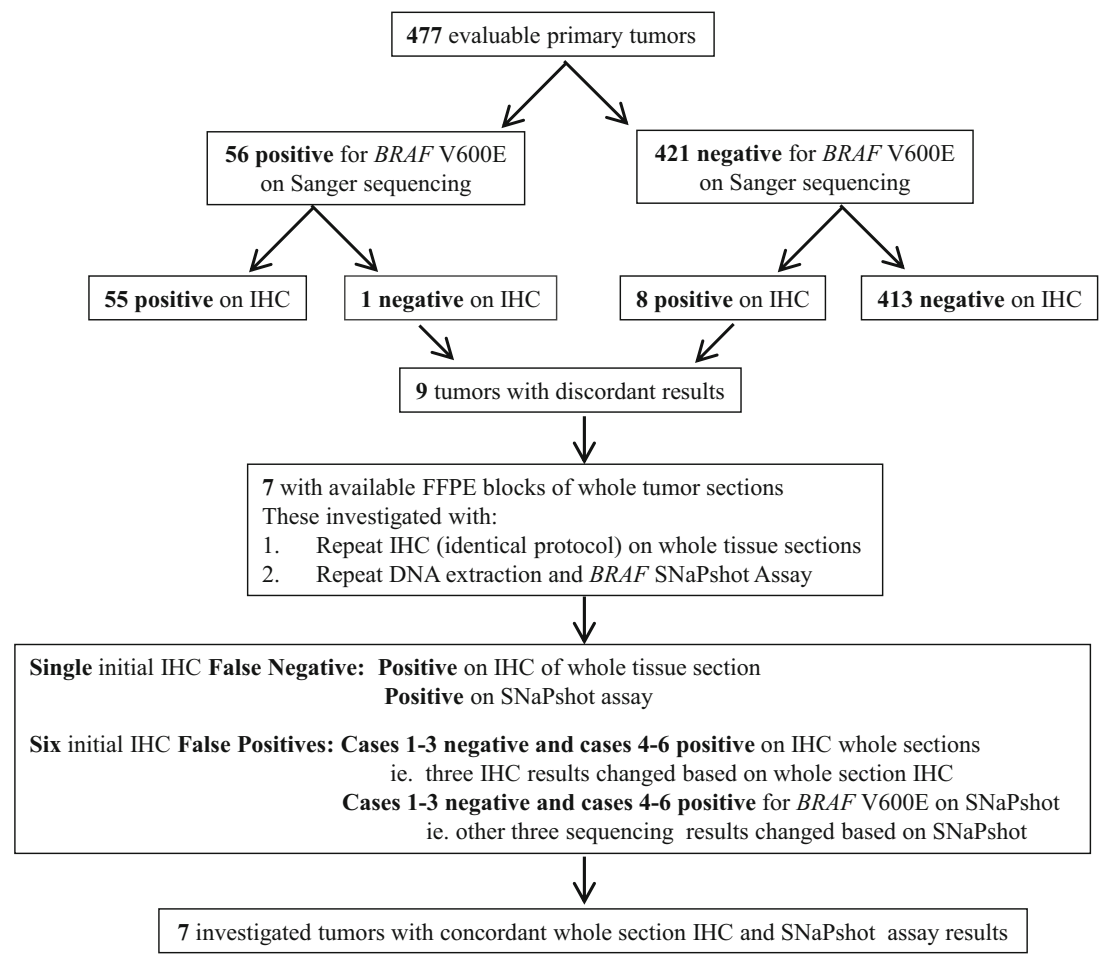

expected, clinical correlations with BRAF V600E positivity confirmed the same patient and tumour associations in this patient cohort seen with $B R A F$ genotype as determined by DNA-based mutation detection methods [38-40], further supporting the validity of this diagnostic approach in community-based patient cohorts. Although we restricted survival data to the subgroup of patients with metastatic disease (either de novo stage IV or recurrent stage IV disease, $n=188$ ), given this is the group of patients for which the presence of a BRAF V600E mutation is a clear prognostic factor, our survival data was again consistent with that seen in other series.

In studies forerunning to those using anti-BRAF antibodies, the ability to apply immunohistochemistry for the detection of mutated gene products has been recognised in the management of gliomas. A monoclonal antibody specific for the mutant protein IDH1 R132H, important diagnostically and prognostically [45], has been developed and applied to clinical

Table 3 Revised determination of $B R A F$ V600E using immunohistochemistry on TMAs and/or whole mount sections versus determination by Sanger sequencing and/or SNaPshot assay

\begin{tabular}{lll}
\hline BRAF V600E results $(n=475)$ & IHC positive & IHC negative \\
\hline Sequencing/SNaPshot positive & $59 a$ & $0 b$ \\
Sequencing/SNaPshot negative & $0 c$ & $416 d$ \\
\hline
\end{tabular}

Sensitivity $(a / a+b)=59 / 59(100 \%)$; specificity $(d / d+c)=416 / 416$ $(100 \%)$; negative predictive value $(d / d+b)=416 / 416(100 \%)$; positive predictive value $(a / a+c)=59 / 59(100 \%)$ samples [46, 47]. Similarly, determination of $B R A F$ mutation status by IHC is anticipated to confer significant benefits in the clinical setting. Unlike genotyping methods, IHC is routinely performed in all hospital histopathology departments. The cost of reagents, equipment and labour is projected to be lower than that of currently available sequencing methods. Additionally, the time to results may be shorter due to the onsite sample processing and absence of requirement for DNA extraction. Routine profiling of all newly diagnosed CRCs for $B R A F$ V600E mutation may therefore now be feasible with an inexpensive and widely available methodology. This takes on added significance when considering $B R A F$ V600E's relatively low population prevalence. Detection of $B R A F \mathrm{~V} 600 \mathrm{E}$ mutation at the time of primary $\mathrm{CRC}$ resection and histopathological analysis has the advantages of excluding underlying

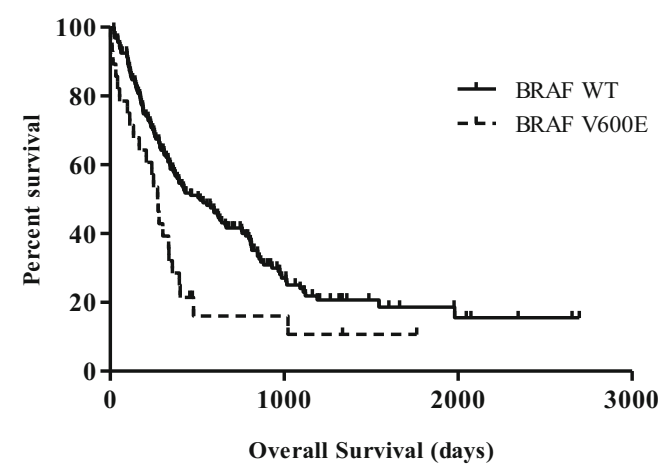

Fig. 6 Overall survival in metastatic colorectal cancer according to $B R A F$ status as determined by IHC 
HNPCC in MSI CRCs [11-13], with resultant screening implications [48], and prevention of lag time awaiting $B R A F$ mutation results in patients later diagnosed with metastatic disease. Given that patients with metastatic $B R A F$-mutant CRC have a significantly poorer prognosis, early recognition of their $B R A F$ status may alter clinical decisions regarding disease observation and, in the future, administration of molecularly directed therapies.

As per the original description of VE1 IHC on clinical samples [18], this study applied both VE1 and pBR1 primary antibodies to all tumours. While VE1 had been selected from 2,234 hybridoma clones as the only immunoglobulin specific for BRAF V600E on IHC, pBR1 had been chosen from panBRAF clones for its demonstrated ability to bind both BRAF wild type and BRAF V600E on IHC and Western blots [18]. The utility of positive pBR1 staining is in its confirmation of BRAF protein expression, reducing the likelihood of falsenegative VE1 IHC findings, i.e. the presence of $B R A F \mathrm{~V} 600 \mathrm{E}$ genotype but negative VE1 staining due to the absence of BRAF protein expression in the tumour. In this cohort, only 14 of 491 primary CRCs $(2.9 \%)$ were negative on pBR1 IHC, suggesting that failure to express $\mathrm{BRAF}$ is rare in $\mathrm{CRC}$ and the routine use of pBR1 concurrently with VE1 may be unnecessary for this tumour type. More important than concurrent pBR1 staining may be preservation of tissue quality, as tissue areas subject to diathermy, showing necrosis, or frozen and then formalin-fixed have all been reported to show lower antigenicity for VE1 [18]. The use of freshly cut tissue sections is also recommended [19]. We noted strong staining of normal colonic surface epithelial cell nuclei for VE1, which could be used as a positive internal control for VE1 IHC protocols. The reason for nuclear staining with the VE1 antibody is unknown.

Immunohistochemistry may be an optimal method for determining the BRAF V600E mutation status of tissue samples with low cellularity due to its single-cell-level resolution. In contrast, for DNA-based detection methods, even microdissected tissue samples contain significant proportions of stromal cell-derived DNA, posing challenges in the detection of diluted tumour cell-derived mutant alleles. BRAF V600Especific IHC has some limitations, however. Samples collected by fine-needle aspiration (FNA) may pose a challenge because of the fixatives used. Caution is urged until the validity of this approach in FNA samples has been adequately investigated. Due to the heterogeneity of VE1 staining seen in a proportion of CRCs, $1.7 \%$ of the evaluable population in this study, small biopsy (e.g. core biopsies) and tissue specimens may be erroneously interpreted due to sampling error. This phenomenon was documented in our patient cohort with the initial use of TMAs for VE1 IHC; for one sample, IHC findings were changed from positive to negative, and for three samples, the reverse occurred when TMA IHC findings were compared to staining on whole mount sections. Although in our patient cohort $<3 \%$ of CRCs were negative on pan-BRAF IHC, other malignancies with low BRAF protein expression may not be amenable to IHC testing. VE1 is highly specific for $B R A F \mathrm{~V} 600 \mathrm{E}$ and does not detect the protein products of other $B R A F$ aa. 600 mutations $[19,27,28]$; hence for diseases with a higher burden of $B R A F$ non-V600E mutations, DNAbased genotyping or alternative monoclonal antibodies may be indicated, particularly should these mutations demonstrate drug sensitivity. In CRC, $<4 \%$ of $B R A F$ mutations are nonV600E $[4,9]$, and no other aa. 600 mutations were detected by sequencing in the 505 patients of this cohort. However, we cannot exclude the possibility that a small number of patients may have carried other non-aa.600 BRAF mutations, as DNA sequencing was limited to the region of aa.600.

Two recently published studies exploring the VE1 antibody in colorectal cancer have also shown a high degree of specificity and sensitivity, but included either small series [32] and/ or a highly preselected patient population [31]. However, the consistent findings in both of these studies add considerable weight to our findings in supporting the incorporation of the antibody as the initial method of detection of BRAF V600E status in patients with colorectal cancer. As opposed to the findings of strong concordance between the VE1 IHC antibody and sequencing-based techniques in these two studies and ours, another study examining VE1 IHC in colorectal cancer was also published recently and reports low sensitivity (71 \%) and specificity ( $74 \%$ ) of VE1 tested on 52 FFPE CRC samples [49]. Methodological differences in the antigen retrieval, staining and signal amplification protocols resulting in poor signal intensity and background staining likely account for this discrepancy [49]. We found that the use of OptiView DAB IHC Detection Kit resulted in clear discrimination between background tissue and BRAF V600E-positive tumour cell cytoplasmic staining using the VE1 antibody. In our experience, patchy focal staining, rather than the level of staining intensity, can lead to difficulties with interpretation, particularly in tissue core samples. Patchy focal staining was occasionally seen $(1.7 \%)$ in otherwise clearly negative tumours and could lead to false-positive results (Fig. 3). Patchy focal non-staining was occasionally seen in otherwise clearly positive tumours and could lead to false-negative results. These staining anomalies were often present in the same areas in restained sections and did not correspond to any anatomical features such as tumour nodules. Interpretive difficulties were often resolved by examining additional tumour areas by staining whole mount sections. In such cases, confirmation of $B R A F$ status should be verified by IHC on a different specimen from that resection or by a sensitive molecular method.

The observation that the vast majority of CRCs stained in this study showed either homogeneously negative or positive BRAF V600E expression argues against the clonal acquisition of $B R A F$ activating mutations in primary CRCs. Interestingly, 
lack of clonality for BRAF V600E expression has also been noted in other malignancies including metastatic lesions [19-21, 28], despite suggestions of polyclonality for $B R A F$ genotype in melanoma and thyroid cancer using alternative experimental methods [50-52]. The use of mutation-specific antibodies to address this controversial cancer biology question is but one of their potential research applications. Busam et al. [53] and Sahm et al. [23] utilised VE1 IHC in co-staining experiments to further characterise $B R A F$ mutation-positive melanocytic lesions and Langerhans cell histiocytosis respectively. Exploration of staining intensity has also been suggested as a potentially fruitful translational research application [54].

In conclusion, the BRAF V600E VE1 antibody is an accurate immunohistochemical diagnostic assay in patients with CRC and should serve as a simple method for the detection of the BRAF V600E mutation in routine practice.

Acknowledgments The authors thank the patients for participating in this study and the Victorian Cancer BioBank and Biogrid Australia for the provision of specimens and access to the clinical data, respectively.

Support This study was supported by the Victorian Government through the Operational Infrastructure Support Program, the Victorian Cancer Agency and the Australian Government through the National Health Medical Research Council and Ventana Medical Systems, Inc. J.D. is supported by the Victorian Government through a Victorian Cancer Agency Clinical Researcher Fellowship. F.D. is supported by the Cancer Council Victoria through a Postgraduate Cancer Research Scholarship.

Conflict of interest JD and PW received funding from Ventana Medical Systems, Inc., for this study to analyse clinical follow-up data and to perform the SNaPShot assays.

Open Access This article is distributed under the terms of the Creative Commons Attribution Noncommercial License which permits any noncommercial use, distribution, and reproduction in any medium, provided the original author(s) and the source are credited.

\section{References}

1. Marshall CJ (1996) Ras effectors. Curr Opin Cell Biol 8:197-204

2. Davies H, Bignell GR, Cox C, Stephens P, Edkins S, Clegg S, Teague J, Woffendin H, Garnett MJ, Bottomley W, Davis N, Dicks E, Ewing $\mathrm{R}$ et al (2002) Mutations of the $B R A F$ gene in human cancer. Nature 417:949-954

3. Simi L, Pratesi N, Vignoli M, Sestini R, Cianchi F, Valanzano R, Nobili S, Mini E, Pazzagli M, Orlando C (2008) High-resolution melting analysis for rapid detection of KRAS, BRAF, and PIK3CA gene mutations in colorectal cancer. Am J Clin Pathol 130:247-253

4. Fumagalli D, Gavin PG, Taniyama Y, Kim SI, Choi HJ, Paik S, Pogue-Geile KL (2010) A rapid, sensitive, reproducible and costeffective method for mutation profiling of colon cancer and metastatic lymph nodes. BMC Cancer 10:101

5. Ogino S, Nosho K, Kirkner GJ, Kawasaki T, Meyerhardt JA, Loda M, Giovannucci EL, Fuchs CS (2009) CpG island methylator phenotype, microsatellite instability, $B R A F$ mutation and clinical outcome in colon cancer. Gut 58:90-96

6. Tie J, Gibbs P, Lipton L, Christie M, Jorissen RN, Burgess AW, Croxford M, Jones I, Langland R, Kosmider S, McKay D, Bollag G, Nolop $\mathrm{N}$ et al (2011) Optimizing targeted therapeutic development: analysis of a colorectal cancer patient population with the $\mathrm{BRAF}^{\mathrm{V} 600 \mathrm{E}}$ mutation. Int J Cancer 128:2075-2084

7. Tran B, Kopetz S, Tie J, Gibbs P, Jiang ZQ, Lieu CH, Agarwal A, Maru DM, Sieber O, Desai J (2011) Impact of BRAF mutation and microsatellite instability on the pattern of metastatic spread and prognosis in metastatic colorectal cancer. Cancer 117:4623-4632

8. Laurent-Puig P, Cayre A, Manceau G, Buc E, Bachet JB, Leconte T, Rougier P, Lievre A, Landi B, Boige C, Ducreux M, Ychou M, Bibeau $\mathrm{F}$ et al (2009) Analysis of PTEN, BRAF, and EGFR status in determining benefit from cetuximab therapy in wild-type $K R A S$ metastatic colon cancer. J Clin Oncol 27:5924-5930

9. De Roock W, Claes B, Bernasconi D, De Schutter J, Biesmans B, Fountzilas G, Kalogeras K, Kotoula V, Papamichael D, Laurent-Puig P, Penault-Llorca F, Rougier P, Vincenzi B et al (2010) Effects of KRAS, BRAF, NRAS, and PIK3CA mutations on the efficacy of cetuximab plus chemotherapy in chemotherapy-refractory metastatic colorectal cancer: a retrospective consortium analysis. Lancet Oncol 11:753-762

10. Bokemeyer C, Van Cutsem E, Rougier P, Ciardiello F, Heeger S, Schlichting M, Celik I, Köhne CH (2012) Addition of cetuximab to chemotherapy as first-line treatment for $K R A S$ wild-type metastatic colorectal cancer: pooled analysis of the CRYSTAL and OPUS randomised clinical trials. Eur J Cancer 48:1466-1475

11. Deng G, Bell I, Crawley S, Gum J, Terdiman JP, Allen BA, Truta B, Sleisenger MH, Kim YS (2004) BRAF mutation is frequently present in sporadic colorectal cancer with methylated hMLH1, but not in hereditary nonpolyposis colorectal cancer. Clin Cancer Res 10:191195

12. Domingo E, Laiho P, Ollikainen M, Pinto M, Wang L, French AJ, Westra J, Frebourg T, Espín E, Armengol M, Hamelin R, Yamamoto $\mathrm{H}$, Hofstra RMW et al (2004) BRAF screening as a low-cost effective strategy for simplifying HNPCC genetic testing. J Med Genet 41: 664-668

13. Robinson KL, Liu T, Vandrovcova J, Halvarsson B, Clendenning M, Frebourg T, Papadopoulos N, Kinzler KW, Vogelstein B, Peltomäki P, Kolodner RD, Nilbert M, Lindblom A (2007) Lynch syndrome (hereditary nonpolyposis colorectal cancer) diagnostics. J Natl Cancer Inst 99:291-299

14. Sanger F, Nicklen S, Coulson AR (1977) DNA sequencing with chain-terminating inhibitors. Proc Natl Acad Sci 47:5463-5467

15. Spittle C, Ward MR, Nathanson KL, Gimotty PA, Rappaport E, Brose MS, Medina A, Letrero R, Herlyn M, Edwards RH (2007) Application of a BRAF pyrosequencing assay for mutation detection and copy number analysis in malignant melanoma. J Mol Diagn 9: 464-471

16. Halait H, Demartin K, Shah S, Soviero S, Langland R, Cheng S, Hillman G, Wu L, Lawrence HJ (2012) Analytical performance of a real-time PCR-based assay for V600 mutation in the BRAF gene, used as the companion diagnostic test for the novel BRAF inhibitor vemurafenib in metastatic melanoma. Diagn Mol Pathol 21:1-8

17. Thomas RK, Baker AC, DeBiasi RM, Winckler W, LaFramboise T, Lin WM, Wang M, Feng W, Zander T, MacConnaill LE, Lee JC, Nicoletti R, Hatton C et al (2007) High throughput oncogene mutation profiling in human cancer. Nat Genet 39:347-351

18. Capper D, Preusser M, Habel A, Sahm F, Ackermann U, Schindler G, Pusch S, Mechtersheimer G, Zentgraf H, von Deimling A (2011) Assessment of BRAF V600E mutation status by immunohistochemistry with a mutation-specific monoclonal antibody. Acta Neuropathol 122:11-19

19. Capper D, Berghoff AS, Magerle M, Ilhan A, Wöhrer A, Hackl M, Pichler J, Pusch S, Meyer J, Habel A, Petzelbauer P, Birner P, von 
Deimling A, Preusser M (2012) Immunohistochemical testing of BRAF V600E status in 1,120 tumor tissue samples of patients with brain metastases. Acta Neuropathol 123:223-233

20. Bullock M, O'Neill C, Chou A, Clarkson A, Dodds T, Toon C, Sywak M, Sidhu SB, Delbridge LW, Robinson BG, Learoyd DL, Capper D, von Deimling A et al (2012) Utilisation of a monoclonal antibody for BRAF ${ }^{\mathrm{V} 600 \mathrm{E}}$ detection in papillary thyroid carcinoma. Endocr Relat Cancer 19:779-784

21. Kopereck O, Kornauth C, Capper D, Berghoff AS, Sari R, Niederle B, von Deimling A, Birner P, Preusser M (2012) Immunohistochemical detection of the BRAF V600E-mutated protein in papillary thyroid carcinoma. Am J Surg Pathol 36:844-850

22. Haroche J, Charlotte F, Arnaud L, von Deimling A, Hélias-Rodzewicz Z, Hervier B, Cohen-Aubart F, Launay D, Lesot A, Mokhtari K, Canioni D, Galmiche L, Rose C et al (2012) High prevalence of BRAF V600E mutations in Erdheim-Chester disease but not in other non-Langerhans cell histiocytoses. Blood 120:2700-2703

23. Sahm F, Capper D, Preusser M, Meyer J, Stenzinger A, Lasitschka F, Berghoff AS, Habel A, Schneider M, Kulozik A, Anagnostopoulos I, Müllauer L, Mechtersheimer G et al (2012) BRAFV600E mutant protein is expressed in cells of variable maturation in Langerhans cell histiocytosis. Blood 120:e28-e34

24. Bösmüller H, Fischer A, Pham DL, Fehm T, Capper D, von Deimling A, Bonzheim I, Staebler A, Fend F (2013) Detection of the BRAF V600E mutation in serous ovarian tumours: a comparative analysis of immunohistochemistry with a mutation-specific monoclonal antibody and allele-specific PCR. Hum Pathol 44:329-335

25. Preusser M, Capper D, Berghoff AS, Horvat R, Wrba F, Schindl M, Schoppmann SF, von Deimling A, Birner P (2013) Expression of BRAF V600E mutant protein in epithelial ovarian tumors. Appl Immunohistochem Mol Morphol 21:159-164

26. Skorokhod A, Capper D, von Deimling A, Enk A, Helmbold P (2012) Detection of BRAF V600E mutations in skin metastases of malignant melanoma by monoclonal antibody VE1. J Am Acad Dermatol 67:488-491

27. Colomba E, Hélias-Rodzewicz Z, von Deimling A, Marin C, Terrones N, Pechaud D, Surel S, Côté JF, Peschaud F, Capper D, Blons H, Zimmermann U, Clerici T et al (2013) Detection of BRAF p.V600E mutations in melanomas. Comparison of four methods argues for sequential use of immunohistochemistry and pyrosequencing. J Mol Diagn 15:94-100

28. Long GV, Wilmott JS, Capper D, Preusser M, Zhang YE, Thompson JF, Kefford RF, von Deimling A, Scolyer RA (2013) Immunohistochemistry is highly sensitive and specific for the detection of V600E BRAF mutation in melanoma. Am J Surg Pathol 2013: $61-65$

29. Ilie M, Long E, Hofman C, Dadone B, Marquette $\mathrm{CH}$, Mouroux J, Vignaud JM, Begueret H, Merlio JP, Capper D, von Deimling A, Emile JF, Hofman P (2013) Diagnostic value of immunohistochemistry for the detection of BRAFV600E mutation in primary lung adenocarcinoma Caucasian patients. Ann Oncol 24:742-748

30. Andrulis M, Penzel R, Weichert W, von Deimling A, Capper D (2012) Application of a BRAF V600E mutation-specific antibody for the diagnosis of hairy cell leukemia. Am J Surg Pathol 36:17961800

31. Sinicrope FA, Smyrk TC, Tougeron D, Thibodeau SN, Singh S, Muranyi A, Shanmugam K, Grogan TM, Alberts SR, Shi Q (2013) Mutation-specific antibody detects mutation $\mathrm{BRAF}^{\mathrm{V} 600 \mathrm{E}}$ protein expression in human colon carcinomas. Cancer 119:2765-2770

32. Toon CW, Walsh MD, Chou A, Capper D, Clarkson A, Sioson L, Clarke S, Mead S, Walters RJ, Clendenning M, Rosty C, Young JP, Win AK et al (2013) BRAFV600E immunohistochemistry facilitates universal screening of colorectal cancers for Lynch Syndrome. Am J Surg Pathol 37:1592-1602

33. van Oers JMM, Lurkin I, van Exsel AJA, Nijsen Y, van Rhijn BWG, van der Aa MNM, Zwarthoff EC (2005) A simple and fast method for the simultaneous detection of nine fibroblast growth factor receptor 3 mutations in bladder cancer and voided urine. Clin Cancer Res 11:7743-7748

34. Lurkin I, Stoehr R, Hurst CD, van Tilborg AAG, Knowles MA, Hartmann A, Zwarthoff EC (2010) Two multiplex assays that simultaneously identify 22 possible mutation sites in the $K R A S, B R A F$, NRAS and PIK3CA genes. PLoS ONE 5:e8802

35. Magnin S, Viel E, Baraquin A, Valmary-Degano S, Kantelip B, Pretet JL, Mougin C, Bigand M, Girardo B, Borg C, Ferrand C (2011) A multiplex $\mathrm{SNaPshot}$ assay as a rapid method for detecting KRAS and $B R A F$ mutations in advanced colorectal cancers. J Mol Diagn 13 : 485-492

36. Altman DG, Bland JM (1994) Diagnostic tests 1: sensitivity and specificity. BMJ 308:1552

37. Altman DG, Bland JM (1994) Diagnostic tests 2: predictive values. BMJ 309:102

38. Samowitz WS, Sweeney C, Herrick J, Albertsen H, Levin TR, Murtaugh MA, Wolff RK, Slatter ML (2005) Poor survival associated with the BRAF V600E mutation in microsatellite-stable colon cancers. Cancer Res 65:6063-6070

39. Li WQ, Kawakami K, Ruszkiewicz A, Bennett G, Moore J, Iacopetta B (2006) BRAF mutations are associated with distinctive clinical, pathological and molecular features of colorectal cancer independently of microsatellite instability status. Mol Cancer 5:2

40. Kalady MF, Dejulius KL, Sanchez JA, Jarrar A, Liu X, Manilich E, Skacel M, Church JM (2012) BRAF mutations in colorectal cancer are associated with distinct clinical characteristics and worse prognosis. Dis Colon Rectum 55:128-133

41. Flaherty KT, Puzanov I, Kim KB, Ribas A, McArthur GA, Sosman JA, O'Dwyer PJ, Lee RJ, Grippo JF, Nolop K, Chapman PB (2010) Inhibition of mutated, activated BRAF in metastatic melanoma. $\mathrm{N}$ Engl J Med 363:809-819

42. Prahallad A, Sun C, Huang S, Di Nicolantonio F, Salazar R, Zecchin D, Beijersbergen RL, Bardelli A, Bernards R (2012) Unresponsiveness of colon cancer to BRAF(V600E) inhibition through feedback activation of EGFR. Nature 483:100-104

43. Corcoran RB, Hiromichi E, Turke AB, Coffee EM, Nishino M, Cogdill AP, Brown RD, Della Pelle P, Dias-Santagata D, Hung KE, Flaherty KT, Piris A, Wargo JA et al (2012) EGFR-mediated reactivation of MAPK signalling contributes to insensitivity of BRAFmutant colorectal cancers to RAF inhibitions with vemurafenib. Cancer Discov 2:227-235

44. Mao M, Tian F, Mariadason JM, Tsao CC, Lemos R, Dayyani F, Vashisht Gopal YN, Jiang ZQ, Wistuba II, Tang XM, Bornman WG, Bollag G, Mills GB et al (2013) Resistance to BRAF inhibition in BRAF-mutant colon cancer can be overcome with PI3K inhibition or demethylating agents. Clin Cancer Res 19:657-667

45. Hartmann C, Meyer J, Balss J, Capper D, Mueller W, Christians A, Felsberg J, Wolter M, Mawrin C, Wick W, Weller M, Herold-Mende $\mathrm{C}$, Unterberg A et al (2009) Type and frequency of IDHI and IDH2 mutations are related to astrocytic and oligodendrial differentiation and age: a study of 1,010 diffuse gliomas. Acta Neuropathol 118: 469-474

46. Capper D, Weißert S, Balss J, Habel A, Meyer J, Jäger D, Ackermann U, Tessmer C, Korshunov A, Zentgraf H, Hartmann C, von Deimling A (2010) Characterization of $\mathrm{R} 132 \mathrm{H}$ mutation-specific IDH1 antibody binding in brain tumors. Brain Pathol 20:245-254

47. Preusser M, Wöhrer A, Stary S, Höftberger R, Streubel B, Hainfellner JA (2011) Value and limitations of immunohistochemistry and gene sequencing for detection of the $I D H 1-R 132 \mathrm{H}$ mutation in diffuse glioma biopsy specimens. J Neuropathol Exp Neurol 70: 715-723

48. Lindor NM, Petersen GM, Hadley DW, Kinney AY, Miesfeldt S, Lu KH, Lynch P, Burke W, Press N (2006) Recommendations for the 
care of individuals with an inherited predisposition to Lynch syndrome. A systematic review. JAMA 296:1507-1517

49. Adackapara CA, Sholl LM, Barletta JA, Hornick JL (2013) Immunohistochemistry using the BRAF V600E mutationspecific monoclonal antibody VE1 is not a useful surrogate for genotyping in colorectal adenocarcinoma. Histopathology 63:187-193

50. Lin J, Takata M, Goto Y, Kido K, Ferrone S, Saida T (2009) Polyclonality of BRAF mutations in acquired melanocytic nevi. J Natl Cancer Inst 101:1423-1427

51. Lin J, Goto Y, Murata H, Sakaizawa K, Uchiyama A, Saida T, Takata M (2011) Polyclonality of BRAF mutations in primary melanoma and the selection of mutant alleles during progression. Br J Cancer $104: 464-468$

52. Guerra A, Sapio MR, Marotta V, Campanile E, Rossi S, Forno I, Fugazzola L, Budillon A, Moccia T, Fenzi G, Vitale M (2012) The primary occurrence of $\mathrm{BRAF}^{\mathrm{V} 600 \mathrm{E}}$ is a rare clonal event in papillary thyroid carcinoma. JCEM 97:517-524

53. Busam KJ, Sung J, Wiesner T, von Deimling A, Jungbluth A (2012) Combined BRAFV600E-positive melanocytic lesions with large epithelioid cells lacking BAP1 expression and conventional nevomelanocytes. Am J Surg Pathol 37:193-199

54. von Deimling A, Sahm F, Capper D (2012) Mutation specific antibodies: tool or dinosaur? Oncotarget 3:907-908 